\title{
CISTO PERIAPICAL INFLAMATÓRIO EM DENTE DECÍDUO: RELATO DE CASO
}

Bruna Maggioni TEIXEIRA, Carolina Lupi GONÇALVES, Aline Akemi MORI, Liogi Iwaki FILHO

O cisto radicular inflamatório é um cisto odontogênico que tem sua origem diretamente ligada a processos inflamatórios, que podem estimular a proliferação de células epiteliais dando início a sua formação. Na maior parte dos casos é assintomático, podendo ser observado tumefação, mobilidade e deslocamento dos dentes adjacentes. Radiograficamente apresenta-se como uma área radiolúcida bem definida, circunscrita por um halo radiopaco contínuo, indicativa de reação óssea no periápice do dente envolvido. O tratamento de escolha mais comum é a enucleação cirúrgica, no entanto, em casos onde os cistos são maiores que $2 \mathrm{~cm}$, pode ser necessário a marsupialização. O objetivo deste trabalho é relatar o caso clínico de uma paciente, 11 anos, gênero feminino, que apresentava ao exame clínico assimetria facial em terço inferior da face. Ao exame intrabucal, o dente 75 apresentava-se com restauração extensa, tratado endodônticamente, cortical óssea vestibular expandida e flutuante à palpação. Ao exame radiográfico, notouse área radiolúcida circunscrita por halo radiopaco. Após estes exames, e feito a punção aspirativa foi optado pela enucleação cirúrgica. O diagnóstico histopatológico foi de cisto periapical inflamatório, tendo como diagnóstico diferencial, principalmente, cisto periapical em dente decíduo, por se tratar de uma patologia rara, queratocisto odontogênico e ameloblastoma unicístico.

Palavras chave: Cisto periapical; Assimetria facial; Odontologia. 